\title{
Assigned experts with competitive goals withhold information in group decision making
}

\author{
Claudia Tomal*, Dimitri Vasiljevic ${ }^{2}$, Dominique Oberlé ${ }^{2}$ \\ and Fabrizio Butera ${ }^{3}$ \\ 'Université catholique de Louvain, Belgium \\ ${ }^{2}$ Université Paris $X$ Nanterre, France \\ ${ }^{3}$ Université de Lausanne, Switzerland
}

\begin{abstract}
Expertise assignment has been proposed to improve unshared information pooling in group decision making. The current research revises this view by hypothesizing that expertise assignment is beneficial when group members have cooperative goals, but is detrimental when group members have competitive goals. Three-person groups were confronted with a hidden-profile task. Members were either assigned experts or not and were instructed to either cooperate or compete with other members. The results confirmed that expertise decreased unshared information pooling and repetitions in competition, while the reverse was found in cooperation. This interaction effect was mediated by self-other difference in perceived competence. Thus, expertise favours or hinders information sharing in group decision making as a function of members' cooperative or competitive goals.
\end{abstract}

Pico della Mirandola and Erasmus of Rotterdam are said to have been the last scholars to know everything; these two exceptional minds, however, lived during the Renaissance, and it is clear today that the development of ideas cannot rely upon one person, but requires experts to become coordinated and complementary information to be pooled (Moscovici, 1993). But do experts really contribute by pooling their superior knowledge in groups?

Past research indicates that groups do not effectively exchange relevant information, and that discussions tend to focus on information that all members know prior to the interaction (Stasser \& Titus, 1985; Wittenbaum \& Stasser, 1996). This is the case for hidden profiles (Stasser \& Titus, 2003) in which optimal decisions are hidden by key pieces of information distributed to different group members (unshared information) while other pieces of information are known to all group members (shared information). In order to solve this problem, expertise assignment (making group members aware of

\footnotetext{
* Correspondence should be addressed to Claudia Toma, Université catholique de Louvain, 10 Place du Cardinal Mercier, I348 Louvain-la-Neuve, Belgium (e-mail: claudia.toma@uclouvain.be).
} 
their respective expertise) has been shown to enhance unshared information pooling (Franz \& Larson, 2002; Stasser, Stewart, \& Wittenbaum, 1995; Stasser, Vaughan, \& Stewart, 2000; Stewart \& Stasser, 1995) because experts' information is considered to be more trustworthy, and important enough to be mentioned during discussions.

However, prior research on hidden profiles has assumed that members always work cooperatively when sharing information (Wittenbaum, Hollingshead, \& Botero, 2004). What has been overlooked is that, in negotiation and many decision-making situations, individuals face a mixture of both cooperative incentives to reach high-quality group decisions and competitive incentives to do well personally (Davis, Laughlin, \& Komorita, 1976; De Dreu, Nijstad, \& van Knippenberg, 2008; De Dreu, Weingart, \& Kwon, 2000). This article integrates the notion of mixed-motives with prior work on expertise and hypothesizes that assigned expertise is beneficial to information pooling when group members have cooperative goals, but might be detrimental when they have competitive goals.

\section{Expertise effects under cooperation and competition}

Studies have shown that in hidden profiles, competition led group members to withhold unshared, but not shared, information (Toma \& Butera, 2009). Thus, we propose that whether group members are in cooperation or in competition should influence the extent to which expertise assignment impacts information sharing. The positive effects of expertise assignment that have been observed in previous research (e.g., Stewart \& Stasser, 1995) would be typical of cooperation, as is also suggested by the research on cooperative learning (Aronson \& Patnoe, 1997).

Classically, expertise is considered a major resource available to the group that can be vital to the group's success (Bottger \& Yetton, 1988). This is because experts exhibit greater levels of participation than other members in group interactions (Bottger, 1984), they talk more and influence the group decision more (Bunderson, 2003; Littlepage, Schmidt, Whisler, \& Frost, 1995; Thomas-Hunt, Ogden, \& Neale, 2003). Moreover, expertise does not need to be real to influence group interactions. Even in the absence of real expertise, individuals thought to have expertise stimulate productive group interaction and information sharing (Wittenbaum, 2000).

In hidden profiles, experts are known to improve unshared information pooling, because they are better able to distinguish task-relevant from task-irrelevant information (Shanteau, 1992). Therefore, they recall unshared information better and are also more motivated to mention it (Franz \& Larson, 2002). Experts are also known to seek out relevant information from other members (Abdolmohammadi \& Shanteau, 1992) and to elicit others' information by repeating it (Franz \& Larson, 2002). In Stasser et al.'s study (1995), three-person groups were presented with the task of solving a homicide mystery. Groups in which members were explicitly informed about their privileged access to unique information (expertise assignment) contributed with more unshared information and led the group to better performances. This is because every group member was aware of each of the other members' responsibilities, and consequently, they coordinated their efforts when sharing unique information. The important point here is that these studies implicitly assumed that the assigned experts were motivated by cooperation.

The original contribution of this research is to provide evidence that when group members are motivated by competition, the well-known positive effects of expertise may be questioned and even reversed. Competition might decrease members' motivation to bring their unique information into discussion, because competition makes people 
more focused on standing out in the comparison of competences with others. In other words, the threat that competition poses to one's own competence may restrict experts when sharing their unique information, and may impair members' motivation to repeat the already-mentioned information. Recent research has revealed that participants who were assigned experts ignored information that was proposed by an equally expert partner, more often when competition was induced than when it was not (Quiamzade \& Mugny, 2009). Therefore, we hypothesize that under competition, groups with assigned expertise should pool and repeat less unshared information than groups without assigned expertise; under cooperation, groups with assigned expertise should pool and repeat more unshared information than groups without assigned expertise (Hypothesis 1 for information pooling and Hypothesis 2 for information repetition).

\section{Perceived competence' and information pooling}

One important mechanism that could explain the differential effect of expertise on information pooling and repetition under cooperation and competition is members' readiness to acknowledge others' competence in comparison with their own. Under cooperation, members with assigned expertise are more likely to view one another as unique individuals with recognized specific competence (Hollingshead, 2000). Under competition, members may want to affirm their competence and deny those of others, and therefore, they might be more focused on standing out from other experts in a comparison of competence (Butera \& Mugny, 2001).

The previous research acknowledges that expertise is beneficial to the group, provided that members feel competent, and recognize other's competence (Markus, Cross, \& Wurf, 1990). When members are unable to identify each one's competence, the potential contributions of experts in groups is reduced (Baumann \& Bonner, 2004; Bunderson, 2003; Littlepage, Robison, \& Reddington, 1997). However, little is known about conditions under which group members are willing (or unwilling) to acknowledge one another's competence, and how this impacts information sharing and repetition. As Littlepage et al. (1995) pointed out, 'it seems important to investigate variables that influence members' ability to recognize expertise'. We believe that whether group members are motivated by cooperation or competition is a critical moderator.

Experts are often afforded status and competence (French \& Raven, 1959) and competition may reinforce members' desire to attain a high status and to prove that their competence is superior to those of others (Stroebe, Diehl, \& Abakoumkin, 1992). Competitive goals are simultaneously associated with the enhancement of selfcompetence and disdain of partners' competence (Darnon, Muller, Schrager, Panuzzo, \& Butera, 2006). The perception of competence is essentially a comparative process, reflecting people's tendency to devaluate or to exaggerate others' competence in a way that minimizes the threat to one's perceived competence (Alicke, LoSchiavo, Zerbst, \& Zhang, 1997). In the context of the current research, expert members in competition may want to prove that others' competence is inferior to their own as a way to maintain their sense of competence. One strategy to maintain this difference with others is to

\footnotetext{
'The notion of perceived competence is conceptually similar to the notion of perceived expertise. Defined as members' ability to recognize others' competence, perceived expertise is an important mediator of group decision-making processes. Similar to perceived competence, perceived expertise is not related to actual expertise and could be influenced by various contextual variables (Littlepage et al., 1995).
} 
neglect mentioning unshared information and to refrain from repeating the alreadymentioned information (see also Buchs \& Butera, 2009; Buchs, Butera, \& Mugny, 2004). Quite the reverse, expert members in cooperation should facilitate the mention and repetition of information, because they should be prone recognizing others' competence as comparable to their own. Thus, we also hypothesize that the self-other difference in perceived competence should mediate the expertise assignment by goals interaction on unshared information pooling and repetition (Hypothesis 3).

\section{Method}

\section{Participants and design}

One hundred forty-four French undergraduate psychology students (122 women and 22 men, $M=19.49$ years, $S D=3.54$ ) participated in this experiment in return for course credit. They were randomly assigned to 48 three-person groups, in a 2 (expertise assignment: yes, no) $\times 2$ (goals: cooperation, competition) factorial design.

\section{Materials and procedure}

We used the materials and procedure designed by Toma and Butera (2009). Participants arrived at the laboratory in groups of three for a study on decision making, and were invited to study a road accident case individually in order to identify the guilty person in the accident. They were provided with 19 shared items and three critical unshared items.

Next, they took part in a round-table discussion, where they were instructed to discuss the accident case for a maximum of $15 \mathrm{~min}$. We adopted the expertise assignment manipulation used by Stasser et al. (1995). In the expertise assignment condition, the experimenter publicly announced that each group member had additional information about one of the suspects. In the no-expertise assignment condition, groups were simply told that each group member did not hold quite the same information. In addition, participants in cooperation and in competition were told that their goal was to jointly decide the best solution regarding the guilty person in the accident. Participants in competition were also told that, although group members make a joint decision, it is important to be the first in the group to propose this solution. Finally, participants completed a post-discussion questionnaire that included questions on their own and others' competence, and manipulation checks.

\section{Dependent measures}

Information sharing

Two measures related to information sharing were computed at the group level. Proportions of shared and unshared information were computed by counting the first mentioned items of shared and unshared information divided by the amount of available shared (19) and unshared items (9). Repetitions were computed by counting the total number of repetitions (separately for shared and unshared information) divided by the number of first-mentioned shared and unshared items, respectively.

Self-other difference in perceived competence

Was computed as the difference between the participant's own estimated competence, and that of the others $(M=2.89, \quad S D=1.38)$, on a 9-point scale ranged from 1 (not at all) to 9 (yes, definitely). A higher positive mean score corresponds to a larger self-other difference in favour of oneself and/or to the disadvantage of others. 
Manipulation checks

Perception of cooperation (three questions, $\alpha=0.96$ ), competition (two questions, $r(46)=.63$ ), and expertise (two questions, $r(46)=.88$ ) were assessed on scales ranged from 1 (not at all) to 9 (yes, definitely). For more details about the method please refer to the Supplemental Materials.

\section{Results}

\section{Manipulation checks}

One group was excluded for having failed to comprehend the instructions. Perceived cooperation was higher in cooperation $(M=8.65, S D=0.34)$ than in competition $(M=7.00, S D=1.19), F(1,43)=41.24, p<.001, \eta_{\mathrm{p}}{ }^{2}=0.49$. Conversely, perceived competition was higher in competition $(M=3.39, S D=1.84)$ than in cooperation $(M=1.71, S D=0.73), F(1,43)=16.32, p<.001, \eta_{\mathrm{p}}{ }^{2}=0.27$. Perception of expertise was higher in expertise assignment condition $(M=3.96, S D=1.51)$ compared to noexpertise assignment condition $(M=3.07, S D=1.18), F(1,43)=7.46, p<.01, \eta_{\mathrm{p}}{ }^{2}=$ 0.14 . No other effects were significant, $p>.05$.

\section{Proportion of information}

Information sharing (proportion and repetition of information) was analysed with a 2 (expertise assignment: yes, no) $\times 2$ (goals: cooperation, competition) $\times 2$ (information type: shared, unshared) mixed ANOVA with repeated measures on the third factor. This analysis revealed the predicted three-way interaction on proportion of information, $F(1,43)=4.43, p<.05, \eta_{\mathrm{p}}{ }^{2}=0.09$. For unshared information, the predicted interaction between expertise assignment and goals was found, $F(1,43)=7.99, p<.01, \eta_{\mathrm{p}}{ }^{2}=$ 0.16. In cooperation, assigned experts exchanged more unshared information $(M=$ $0.93, S D=0.06)$ than unassigned experts $(M=0.83, S D=0.13), F(1,43)=5.90$, $p<.05, \eta_{\mathrm{p}}{ }^{2}=0.05$, while in competition, assigned experts exchanged less unshared information $(M=0.45, S D=0.17)$ than unassigned experts $(M=0.63, S D=0.26)$, $F(1,43)=3.79, p=.06, \eta_{\mathrm{p}}{ }^{2}=0.06$ (Figure 1). For shared information, the interaction between expertise assignment and goals was not significant, $F<1$.

\section{Rate of information repetition}

Concerning the repetition of information, the three-way interaction between expertise assignment, goals, and information type was also significant, $F(1,43)=13.65, p<$ $.001, \eta_{\mathrm{p}}{ }^{2}=0.25$. For unshared information, the predicted interaction between expertise assignment and goals was found, $F(1,43)=10.75, p<.01, \eta_{\mathrm{p}}{ }^{2}=0.20$. In cooperation, assigned experts repeated more unshared information $(M=2.75, S D=0.58)$ than unassigned experts $(M=1.79, S D=1.05), F(1,43)=6.03, p<.05, \eta_{\mathrm{p}}{ }^{2}=0.08$, while in competition, assigned experts repeated less unshared information $(M=.60, S D=$ $0.52)$ than unassigned experts $(M=1.38, S D=1.12), F(1,43)=4.77, p<.05, \eta_{\mathrm{p}}{ }^{2}=$ 0.05 . For shared information, the interaction between expertise assignment and goals was significant, $F(1,43)=4.28, p<.05, \eta_{\mathrm{p}}{ }^{2}=0.09$. In cooperation, there was no difference between assigned experts $(M=0.44, S D=0.41)$ and unassigned experts $(M=0.55, S D=0.27), F<1$, while in competition, assigned experts repeated more 


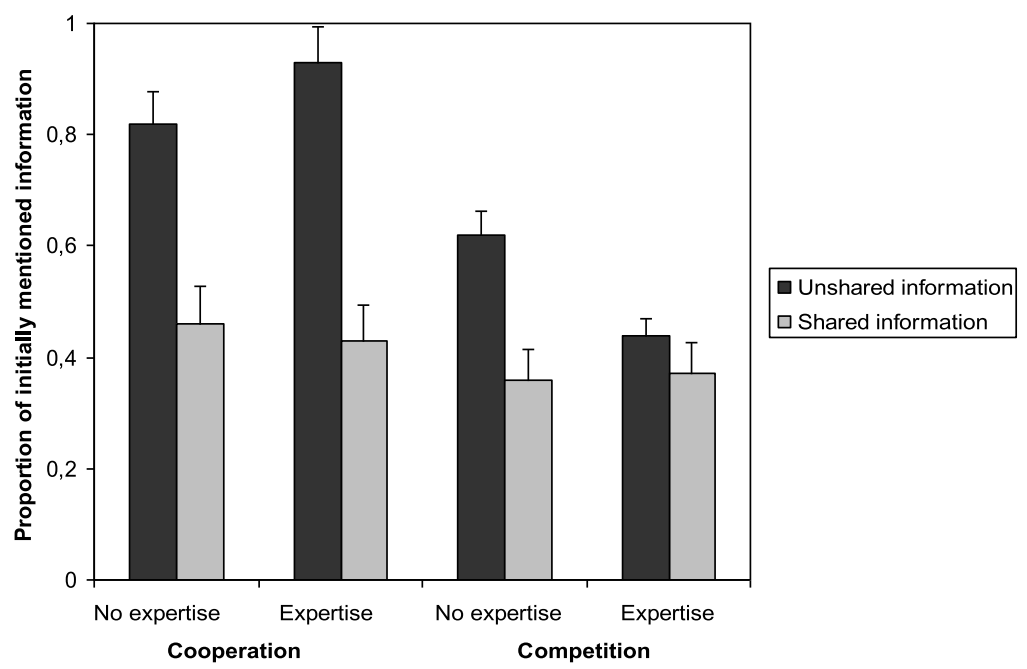

Figure I. Proportion of initially mentioned unshared and shared information as a function of expertise assignment and goals.

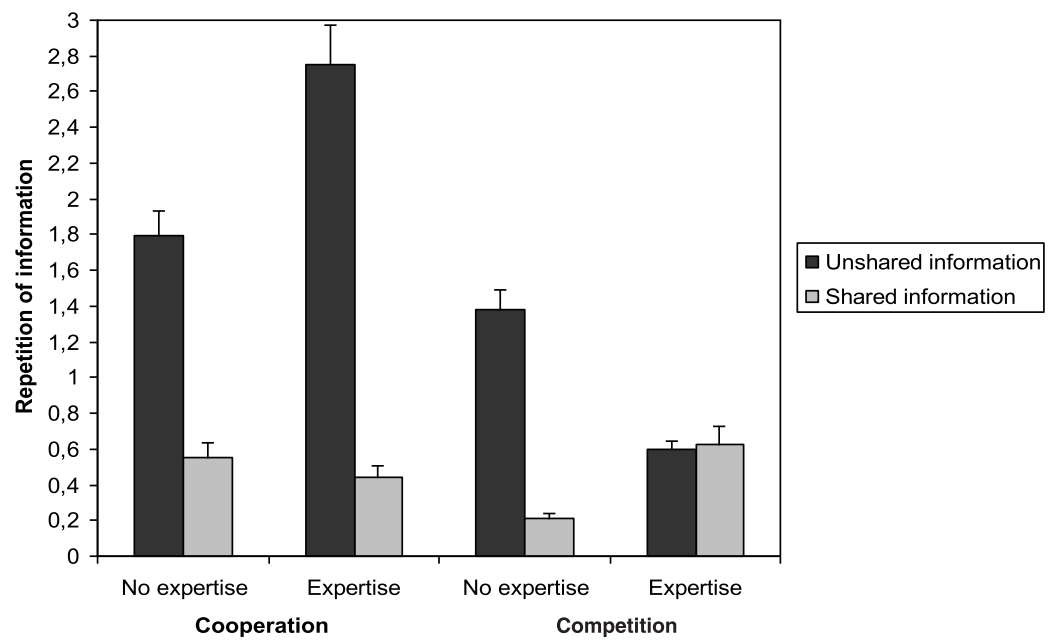

Figure 2. Repetition of unshared and shared information as a function of expertise assignment and goals.

shared information $(M=0.63, S D=0.64)$ than unassigned experts $(M=0.21, S D=0.21)$, $F(1,43)=3.71, p=.06, \eta_{\mathrm{p}}{ }^{2}=0.04$ (Figure 2). 
Table I. Least square regression results for the mediated moderation model for the proportion of unshared information

\begin{tabular}{|c|c|c|c|c|c|c|}
\hline \multirow[b]{2}{*}{ Predictors } & \multicolumn{2}{|c|}{$\begin{array}{c}\text { Equation I } \\
\text { (criterion PROPUINFO) }\end{array}$} & \multicolumn{2}{|c|}{$\begin{array}{c}\text { Equation } 2 \\
\text { (criterion PERCOMP) }\end{array}$} & \multicolumn{2}{|c|}{$\begin{array}{c}\text { Equation } 3 \\
\text { (criterion PROPUINFO) }\end{array}$} \\
\hline & $\beta$ & $t$ & $\beta$ & $t$ & $\beta$ & $t$ \\
\hline Expertise & -0.08 & -0.76 & 0.14 & 1.14 & 0.03 & 0.29 \\
\hline Goals & 0.69 & $6.93^{*}$ & -0.40 & $-3.21^{* *}$ & 0.60 & $5.74^{* *}$ \\
\hline Expertise $\times$ goals & 0.28 & $2.83^{* *}$ & -0.36 & $-2.87^{* *}$ & 0.17 & 1.62 \\
\hline PERCOMP & & & & & -0.24 & $-2.10^{* * *}$ \\
\hline PERCOMP $\times$ goals & & & & & 0.18 & $\mathrm{I} .75$ \\
\hline
\end{tabular}

Note. PROPUINFO $=$ proportion of unshared information, PERCOMP $=$ perception of self-other competence. ${ }^{*} p<.00 \mathrm{I} ;{ }^{* *} p<.01 ;{ }^{* * *} p<.05$.

Table 2. Least square regression results for the mediated moderation model for the repetition of unshared information

\begin{tabular}{|c|c|c|c|c|c|c|}
\hline \multirow[b]{2}{*}{ Predictors } & \multicolumn{2}{|c|}{$\begin{array}{c}\text { Equation I } \\
\text { (criterion REPUINFO) }\end{array}$} & \multicolumn{2}{|c|}{$\begin{array}{c}\text { Equation } 2 \\
\text { (criterion PERCOMP) }\end{array}$} & \multicolumn{2}{|c|}{$\begin{array}{c}\text { Equation } 3 \\
\text { (criterion REPUINFO) }\end{array}$} \\
\hline & $\beta$ & $t$ & $\beta$ & $t$ & $\beta$ & $t$ \\
\hline Expertise & 0.04 & 0.33 & 0.14 & 1.14 & 0.01 & 0.04 \\
\hline Goals & 0.54 & $4.80^{*}$ & -0.40 & $-3.21^{* *}$ & 0.39 & $3.42^{* *}$ \\
\hline Expertise $\times$ goals & 0.37 & $3.28^{* *}$ & -0.36 & $-2.87^{* *}$ & 0.27 & $2.40^{* * *}$ \\
\hline PERCOMP & & & & & -0.38 & $-3.08^{* *}$ \\
\hline PERCOMP $\times$ goals & & & & & -0.22 & -1.95 \\
\hline
\end{tabular}

Note. REPUINFO $=$ repetition of unshared information, PERCOMP $=$ perception of self-other competence. ${ }^{*} p<.001 ;{ }^{* *} p<.01 ;{ }^{* * *} p<.05$.

\section{The mediational role of self-other difference in perceived competence ${ }^{2}$ on pooling and repetition of unshared information}

We followed the procedure set forth by Muller, Judd, and Yzerbyt (2005). In equation 1 (see Table 1 and Table 2), the overall moderation was found on the proportion of unshared information, $B=0.28, S E=0.09$ and on the repetition of unshared information,

\footnotetext{
${ }^{2}$ In order to understand the origin of the variations in perceived competence score, we analyzed self-competence and other competence separately, with a 2 (expertise assignment: yes, no) $\times 2$ (goals: cooperation, competition) $\times 2$ (target: self, others) ANOVA with repeated measure on the last factor. This analysis revealed a significant three-way interaction, $F(I, 43)$ $=10.49, p<.001, \eta_{p}{ }^{2}=0.19$. For perceived self-competence, group members perceived themselves as more competent in competition $(M=6.28, S D=2.02)$ than in cooperation $(M=5.29, S D=I .55), F(I, 43)=3.73, p=.06, \eta_{p}{ }^{2}=0.08$; and more competent with assigned expertise $(M=6.30, S D=1.77)$ than without assigned expertise $(M=5.27, S D=$ I.83), $F(I, 43)=4.05, p<.05, \eta_{p}{ }^{2}=0.08$. For perceived other competence, the analysis revealed a significant two-way interaction, $F(I, 43)=10.37, p<.0 I, \eta_{p}{ }^{2}=0.19$. In cooperation, members with assigned expertise were perceived as more competent $(M=3.86, S D=I .7 I)$ than members without assigned expertise $(M=2.09, S D=I .07), F(I, 43)=9.16, p<$ $.01, \eta_{p}{ }^{2}=0.17 . I n$ competition, members with assigned expertise were perceived as less competent $(M=2.27, S D=0.88)$ than members without assigned expertise $(M=3.25, S D=I .28), F(I, 43)=4.67, p<.05, \eta_{p}^{2}=0.07$. This analysis suggests that the variations in the perceived competence score are due to the devaluation of other competence rather than the enhancement of self-competence. However, because the perception of self-other competence is a comparative process, we decided to use the difference score in the mediation analysis. The analysis also holds when using the perception of others' competence as mediator.
} 
$B=1.74, S E=0.53$. In equation 2 , the overall moderation was found on perceived competence, $B=-1.98, S E=0.69$. In equation 3 , when controlling for perceived competence, both the overall moderation on the proportion of information, and of the repetition of information, were reduced, $B=0.16, S E=0.10$ and $B=1.26, S E=0.52$, respectively, while perceived competence still predicted the proportion of unshared information, $B=-0.04, S E=0.02$, and the repetition of unshared information, $B=$ $-0.32, S E=0.10$. Moreover, the residual of the moderation of goals and expertise assignment was reduced from $B=0.28$ to $B=0.16$ on information pooling, and from $B=1.74$ to $B=1.26$ on information repetition. The Sobel tests were significant, $z=$ $2.44, p<.05$ and $z=2.76, p<.01$, respectively.

\section{Group decision quality}

As is common practice in the literature on hidden profiles, we also analyzed group decision quality. The results indicated that in cooperation, more groups succeeded (91\%) than failed (9\%), whereas in competition, more groups failed $(96 \%)$ than succeeded (4\%), $\chi^{2}(1, N=47)=35.82, p<.001$. Although the interaction between goals and expertise was not significant $\left(\chi^{2}<1\right)$, an approach in terms of group productivity (i.e., the time used by the group to make a decision; Steiner, 1972) can offer a clearer picture. We therefore analysed the discussion time with a 2 (expertise assignment: yes, no) $\times 2$ (goals: cooperation, competition) ANOVA. The two-way interaction was significant, $F(1,43)=7.95, p<.01, \eta_{\mathrm{p}}{ }^{2}=0.15$. For competitive groups, discussion time is longer with assigned expertise $(M=192.75 \mathrm{~s}, S D=99.46)$ than without assigned expertise $(M=113.50, S D=80.76), F(1,43)=4.59, p<.05, \eta_{\mathrm{p}}{ }^{2}=0.09$, while for cooperative discussion time was shorter with assigned expertise $(M=95.27, S D=20.34)$ than without assigned expertise $(M=133.17, S D=54.64), F(1,43)=4.68, p<.05$, $\eta_{\mathrm{p}}{ }^{2}=0.10$. The main effects were not significant, $F \mathbf{s}<1$. All cooperative/competitive groups performed well/poorly in making a good decision, but expertise assignment reduced/increased the time needed for this decision. For more detailed analyses please refer to the Supplemental Materials.

\section{Discussion}

Traditionally, the research on hidden profiles has assumed that, when making decisions, group members work cooperatively but exchange information in a biased manner (Stasser, 1999), and that expertise assignment is a leading resource in improving information sharing (Stasser et al., 1995). In the current research, we proposed to revise this perspective by hypothesizing that expertise can have both positive and negative effects on information sharing, depending on members' goals; this is an important specification, given that experts are often used in all types of workgroups to improve the quality of members' interactions.

First, we replicated the results of previous research by Toma and Butera (2009), by demonstrating that under competition, groups mentioned and repeated less unshared information and made decisions of a lower quality than in cooperation, bringing supplementary support to the view of groups as motivated information processors (De Dreu et al., 2008; Toma \& Butera, 2009; Toma, Bry, \& Butera, in press; Toma, Gilles, \& Butera, 2011; Wittenbaum et al., 2004). More importantly, we provided evidence that the effects of expertise assignment on unshared information pooling and repetition 
depended on goals. We replicated the well-known positive effects of expertise only in cooperation, while a reverse effect was found in competition. Cooperative groups with assigned expertise pooled and repeated more unshared information than did groups without assigned expertise, while competitive groups with assigned expertise pooled less unshared information than did groups without assigned expertise (Hypothesis 1 and Hypothesis 2).

The reason for this effect appears to be related to the self-other difference in perceived competence (Hypothesis 3), which mediated the expertise assignment by goal interaction effect. This result lends support to the conceptual analysis of Hypothesis 1 and Hypothesis 2 that the differential effect of expertise assignments could be due to the fact that in competition, more so than in cooperation, group members might strive to maintain the difference in competence with others by neglecting to mention or repeat relevant information. Although we can only speculate on this, we surmise that the difference in perceived competence could even reflect a threat to competence. The social comparative literature has long shown that enhanced self-competence occurs when others' competence is perceived as a threat for one's own (Hackmiller, 1966; Wills, 1981). Recent research has even pinpointed that when compared to a specific other, contrary to the better-than-average effect, people tend to report that they are equal, and in some cases even inferior, to the target (Alicke, Klotz, Breitenbecher, Yurak, \& Vredenburg, 1995), unless their competence is threatened, in which case they claim their superiority (Muller \& Butera, 2004). However, the mediation is only partial with regard to repetition, suggesting that other mechanisms might explain experts' information pooling. One possibility is that competitive groups with assigned experts endorsed less critical thinking than did cooperative groups (Postmes, Spears, \& Cihangir, 2001), and therefore, they repeated more unshared information. Another possibility is that competitive groups exhibited a higher level of mistrust and were therefore less motivated to mention and repeat unshared information than were cooperative groups. Under competition, assigned experts may have withheld unshared information, but not shared information, probably in a tactical attempt to deal with mistrust and the fear of being exploited (Steinel \& De Dreu, 2004; Toma \& Butera, 2009).

Although this research promotes our understanding of the role of expertise on information sharing, it also raises questions about the notion of expertise. Our study defined experts as those individuals who possessed more information about a particular decision alternative (Stasser et al., 1995). We acknowledge that this definition does not fully account for expertise that could also be defined as particular knowledge about a specific domain (MacCrimmon \& Wagner, 1987), past task performance (Shanteau, 1987), and familiarity with the task (Smith \& Kida, 1991). Future research should manipulate the different forms of expertise in order to investigate the generalizability of our findings.

Despite this limitation, our research suggests that expertise assignment can have both beneficial and detrimental effects on information sharing, depending on members' goals. For this reason, we advise caution when inviting experts to make decisions with high individual stakes, because this may lead to in-group competition and information withholding. Moreover, the self-other difference in perceived competence is a key mechanism that explains why assigned experts could withhold their unshared information when pursuing competitive, rather than cooperative, goals. Expertise assignment alone is not a guarantee of success when creating professional and research teams. 


\section{Acknowledgements}

We thank Stéphanie Demoulin and Benoit Dompnier for their comments. The Swiss National Science Foundation supported this work.

\section{References}

Abdolmohammadi, M. J., \& Shanteau, J. (1992). Personal attributes of expert auditors. Organizational Behavior and Human Decision Processes, 53, 158-172. doi:10.1016/07495978(92)90060-K

Alicke, M. D., Klotz, M. L., Breitenbecher, D. L., Yurak, T. J., \& Vredenburg, D. S. (1995). Personal contact, individuation, and the better-than-average effect. Journal of Personality and Social Psychology, 68, 804-825. doi:10.1037/0022-3514.68.5.804

Alicke, M. D., LoSchiavo, F. M., Zerbst, J. I., \& Zhang, S. (1997). The person who outperforms me is a genius: Maintaining perceived competence in upward social comparison. Journal of Personality and Social Psychology, 73, 781-789. doi:10.1037/0022-3514.73.4.781

Aronson, E., \& Patnoe, S. (1997). The jigsaw classroom: Building cooperation in the classroom (2nd ed.). New York: Addison Wesley Longman.

Baumann, M. R., \& Bonner, B. L. (2004) Expertise in collective decision-making: Variability, expectations, and utilization. Organizational Behavior and Human Decision Processes, 93, 89-101. doi:10.1016/j.obhdp.2003.12.004

Bottger, P. C. (1984). Expertise and air time as basis of actual and perceived influence in problem solving groups. Journal of Applied Psychology, 69, 214-221. doi:10.1037/0021-9010.69.2.214

Bottger, P. C., \& Yetton, P. W. (1988). An integration of process and decision scheme explanations of group problem solving performance. Organizational Behavior and Human Decision Processes, 42, 234-249. doi:10.1016/0749-5978(88)90014-3

Buchs, C., \& Butera, F. (2009), Is a partner's competence threatening during dyadic cooperative work? It depends on resource interdependence. European Journal of Psychology of Education, 24, 145-154. doi:10.1007/BF03173007

Buchs, C., Butera, F., \& Mugny, G. (2004). Resource in(ter)dependence, student interactions and performance in cooperative learning. Educational Psychology, 24, 291-314. doi:10.1080/ 0144341042000211661

Bunderson, J. S. (2003). Recognizing and utilizing expertise in work groups: A status characteristics perspective. Administrative Science Quarterly, 48, 557-591.

Butera, F., \& Mugny, G. (2001). Conflicts and social influences in hypothesis testing. In C. De Dreu \& N. De Vries (Eds.), Group consensus and minority influence: Implications for innovation (pp. 160-182). Oxford: Blackwell.

Darnon, C., Muller, D., Schrager, S., Pannuzzo, N., \& Butera, F. (2006). Mastery and performance goals predict epistemic and relational conflict regulation. Journal of Educational Psychology, 98, 766-776. doi:10.1037/0022-0663.98.4.766

Davis, J. H., Laughlin, P. R., \& Komorita S. S. (1976). The social psychology of small groups. Annual Review of Psychology, 27, 501-541.

De Dreu, C. K. W., Nijstand, B. A., \& van Knippenberg, D. (2008). Motivated information processing in group judgment and decision making. Personality and Social Psychology Review, 12, $22-$ 49. doi:10.1177/1088868307304092

De Dreu, C. K. W., Weingart, L. R., \& Kwon, S. (2000). Influence of social motives on integrative negotiation: A meta-analytical review and test of two theories. Journal of Personality and Social Psychology, 78, 889-905. doi:10.1037/0022-3514.78.5.889

Franz, T. M., \& Larson, J. R., Jr. (2002). The impact of experts on information sharing during group discussion. Small Group Research, 33, 383-411. doi:10.1177/104649640203300401

French, J. R. P., \& Raven, B. H. (1959). The bases of social power. In D. Cartwright (Ed.), Studies in social power (pp. 150-167). Ann Arbor, MI: University of Michigan. 
Hakmiller, K. L. (1966). Threat as a determinant of downward comparison. Journal of Experimental Social Psychology, Supplement 1, 32-39.

Hollingshead, A. B. (2000). Perceptions of expertise and transactive memory in work relationships. Group Processes and Intergroup Relations, 3, 257-267. doi:10.1177/1368430200033002.

Littlepage, G., Robison, W., \& Reddington, K. (1997). Effects of task experience and group experience on group performance, member ability, and recognition of expertise. Organizational Behavior and Human Decision Processes, 69(2), 133-147. doi:10.1006/obhd.1997.2677

Littlepage, G. E., Schmidt, G. W., Whisler, E. W., \& Frost, A. G. (1995). An input-process-output analysis of influence and performance in problem-solving groups. Journal of Personality and Social Psychology, 69, 877-889. doi:10.1006/obhd.1997.2677

MacCrimmon, K. R., \& Wagner, C. (1987). Expert systems and creativity. In J. L. Mumpower, L. D. Phillips, O. Renn, \& V. R. R. Uppuluri (Eds.), Expert judgment and expert systems (pp. 173-193). Berlin: Springer-Verlag.

Markus, H., Cross, S., \& Wurf, E. (1990). The role of the self-system in competence. In R. J. Sternberg \& J. Kolligian, Jr. (Eds.), Competence considered (pp. 205-225). New Haven, CT: Yale University Press.

Moscovici, S. (1993). Toward a social psychology of science. Journal for the Theory of Social Behaviour, 23, 343-374.

Muller, D., \& Butera, F. (2004). On being concerned about bragging. Current Psychology of Cognition, 22, 159-179.

Muller, D., Judd, C. M., \& Yzerbyt, V. Y. (2005). When moderation is meditated and when mediation is moderated. Journal of Personality and Social Psychology, 89, 852-863. doi: $10.1037 / 0022-3514.89 .6 .852$

Postmes, T., Spears, R., \& Cihangir, S. (2001). Quality of decision making and group norms. Journal of Personality and Social Psychology, 80, 918-930. doi:10.1037//0022-3514.80.6.918

Quiamzade, A., \& Mugny, G. (2009). Social influence and threat in confrontations between competent peers. Journal of Personality and Social Psychology, 97, 652-666. doi:10.1037/a0015822

Shanteau, J. (1987). Psychological characteristics of expert decision makers. In J. L. Mumpower, O. Renn, L. D. Phillips, \& V. R. R. Uppuluri (Eds.), Expert judgment and expert systems (pp. 289-304). Berlin: Springer-Verlag.

Shanteau, J. (1992). Competence in experts: The role of task characteristics. Organizational Behavior and Human Decision Processes, 53, 252-266. doi:10.1016/0749-5978(92)90064-E

Smith, J. F., \& Kida, T. (1991). Heuristics and biases: Expertise and task realism in auditing. Psychological Bulletin, 109, 472-489. doi:10.1037/0033-2909.109.3.472

Stasser, G. (1999). The uncertain role of unshared information in collective choice. In L. L. Thompson, J. M. Levine, \& D. M. Messick (Eds.), Shared cognition in organizations: The management of knowledge (pp. 49-69). Mahwah, NJ: Lawrence Erlbaum Associates, Publishers.

Stasser, G., Stewart, D. D., \& Wittenbaum, G. M. (1995). Expert roles and information exchange during discussion: The importance of knowing who knows what. Journal of Experimental Social Psychology, 31, 244-265. doi:10.1006/jesp.1995.1012

Stasser, G., Taylor, L. A., \& Hanna, C. (1989). Information sampling in structured and unstructured discussions of three- and six-person groups. Journal of Personality and Social Psychology, 57, 67-78. doi:10.1037/0022-3514.57.1.67

Stasser, G., \& Titus, W. (1985). Pooling of unshared information in group decision making: Biased information sampling during discussion. Journal of Personality and Social Psychology, 48, 1467-1478. doi:10.1037/0022-3514.48.6.1467

Stasser, G., \& Titus, W. (2003). Hidden profiles: A brief history. Psychological Inquiry, 14, 304313.

Stasser, G., Vaughan, S. I., \& Stewart, D. D.(2000). Pooling unshared information: The benefits of knowing how access to information is distributed among group members. Organizational Behavior and Human Decision Processes, 82, 102-116. doi:10.1006/obhd.2000.2890 
Steinel, W., \& De Dreu, C. K. W. (2004). Social motives and strategic misrepresentation in social decision making. Journal of Personality and Social Psychology, 86, 419-434. doi:10.1037/ 0022-3514.86.3.419

Steiner, I. D. (1972). Group process and productivity. New York: Academic Press.

Stewart, D. D., \& Stasser, G. (1995). Expert role assignment and information sampling during collective recall and decision making. Journal of Personality and Social Psychology, 69, 619-628. doi:10.1037/0022-3514.69.4.619

Stroebe, W., Diehl, M., \& Abakoumkin, G. (1992). The illusion of group effectivity. Personality and Social Psychology Bulletin, 18, 643-650.

Thomas-Hunt, M. C., Ogden, T. Y., \& Neale, M. A. (2003). Who's really sharing? Effects of social and expert status on knowledge exchange within groups. Management Science, 49, 464-477.

Toma, C., Bry, C., \& Butera, F. (in press). Because I'm worth it! (more than others . . .): Cooperation, competition and ownership bias in group-decision making. Social Psychology.

Toma, C., \& Butera, F. (2009). Hidden profiles and concealed information. Strategic information sharing and use in group decision making. Personality and Social Psychology Bulletin, 35, 793-806. doi:10.1177/0146167209333176

Toma, C., Gilles, I., \& Butera, F. (2011). Strategic use of preference confirmation in group decision making: the role of competition and dissent. British Journal of Social Psychology. Advance online publication. doi:10.1111/j.2044-8309.2011.02037.x

Wills, T. A. (1981). Downward comparison principles in social psychology. Psychological Bulletin, 90, 245-271.

Winquist, J. R., \& Larson, J. R., Jr. (1998). Information pooling: When it impacts group decision making. Journal of Personality and Social Psychology, 74, 371-377. doi:10.1037/0022-3514. 74.2.371

Wittenbaum, G. M. (2000). The bias toward discussing shared information: Why are high status group members immune? Communication Research, 27, 379-401. doi:10.1177/ 009365000027003005

Wittenbaum, G. M., Hollingshead, A. B., \& Botero, I. C. (2004). From cooperative to motivated information sharing in groups: moving beyond the hidden profile paradigm. Communication Monographs, 71, 286-310

Wittenbaum, G. M., Merry, C. J., \& Stasser, G. (1996). Tacit coordination in anticipation of small group task completion. Journal of Experimental Social Psychology, 32, 129-152. doi:10.1006/jesp.1996.0006

Wittenbaum, G. M., \& Stasser, G. (1996). Management of information in small groups. In: A. M. Brower \& J.L. Nye (Eds.). What's social about social cognition? Research on socially shared cognition in small groups (pp. 3-28). Thousand Oaks, CA: Sage Publications.

Received 5 July 20II; revised version received 19 March 2012 